\title{
Influence of operational parameters on the fluid-side mass transfer resistance observed in a packed bed bioreactor
}

\author{
Amir Hussain ${ }^{1}$, Martin Kangwa', Ahmed Gad Abo-Elwafa² and Marcelo Fernandez-Lahore ${ }^{\text {** }}$
}

\begin{abstract}
The influence of mass transfer on productivity as well as the performance of packed bed bioreactor was determined by varying a number of parameters; flow rate, glucose concentration and polymers (chitosan). Saccharomyces cerevisiae cells were immobilized in chitosan and non-chitosan coated alginate beads to demonstrate the effect on external mass transfer by substrate consumption time, lag phase and ethanol production. The results indicate that coating has a significant effect on the lag phase duration, being 30-40 min higher than non-coated beads. After lag phase, no significant change was observed in both types of beads on consumption of glucose with the same flow rate. It was observed that by increasing flow rates; lag phase and glucose consumption time decreased. The reason is due to the reduction of external mass transfer as a result of increase in flow rate as glucose is easily transported to and from the beads surface by diffusion. It is observed that chitosan acts as barrier for transfer of substrate and products, in and out of beads, at initial time of fermentation as it shows longer lag phase for chitosan coated beads than non-coated. Glucose consumption at low flow rate was lower as compared to higher flow rates. The optimum combination of parameters consisting of higher flow rates $30-90 \mathrm{ml} / \mathrm{min}$ and between 10 and $20 \mathrm{~g} / \mathrm{l}$ of glucose was found for maximum production of ethanol.
\end{abstract}

Keywords: Packed bed reactor, External mass transfer, Saccharomyces cerevisiae, Alginate, Chitosan, Glucose

\section{Introduction}

The increase in fossil fuel usage has resulted in both environmental and health problems due to pollutants produced (Shafiee and Topal 2008). This effect has encouraged researchers in finding alternative, less/ non-pollutant cheaper fuel sources like ethanol. Therefore, the use of (bio) ethanol as a fuel has been widely encouraged. The most favored method in ethanol production is through the use of yeast Saccharomyces cerevisiae fermentation process in bioreactors (Pscheidt and Glieder 2008; de Jong et al. 2012; Cha et al. 2014; Djordjevic et al. 2014). For many centuries, yeast wholecells have profoundly been used as a work horse in the production of bioethanol and it is currently the most

\footnotetext{
*Correspondence: m.fernandez-lahore@jacobs-university.de 1 Downstream Bioprocessing Laboratory, School of Engineering and Science, Jacobs University, Campus Ring 1, 28759 Bremen, Germany Full list of author information is available at the end of the article
}

used microorganism due to its extensively high rate of fermentation of sugars and its high tolerance to byproducts produced during fermentation (Matsushika et al. 2009; Hasunuma and Kondo 2012; De Bari et al. 2013; Borovikova et al. 2014). However, as the demand in biofuel increases, there is need in finding both the best bioreactor and fermentation conditions that favor's higher production and quality. Bioreactors have found their extensive usage in biotechnology and are assimilated in the heart of biotechnological process, being the equipment in which the substrate is effectively bio-converted to the desired products under the microbial cells or enzyme activity (Pilkington et al. 1998; Yu et al. 2007; Crespo et al. 2012; de Jong et al. 2012; Lee et al. 2012; Mathew et al. 2014).

For the past decades researchers have focused both on selecting the best favorable strains for bioconversion as while as in the design of the best bioreactors. To achieve high, effective and economically commercialized

\section{Springer}


industrial production of bioethanol and other bioproducts, there is need to use a bioreactor with immobilized cells and, having an enhanced flow regime that, in turn, will minimize mass transfer limitations. Therefore, the study on the influence of mass transfer on productivity as well as the performance of bioreactor is still needed. These factors are severely affected by both external mass transfer limitations (transfer of reactants to and products from immobilized cell system) and internal mass transfer limitations (rate of transport inside the system (Saini and Vieth 1975; Converti et al. 1985; Anselme and Tedder 1987; Galaction et al. 2011). Cell immobilization technology, the localization of intact cells to a defined region of space with the preservation of catalytic activity presents for the biochemical process industry a radical advance, similar to the introduction of heterogeneous catalysis in the petrochemical and heavy chemical industries (Yu et al. 2007; Willaert and Flickinger 2009; Duarte et al. 2013). This justifies the interest in the research and development advanced materials for biotechnology with the combined effort of scientists from various fields to obtain polymers with well-defined structures and specific chemical, physicochemical, mechanical and biological properties which are used in cell enzyme entrapments (Terada et al. 2006; Duarte et al. 2013). The immobilization technique has found numerous advantages over free cells such as easiness of product separation, reutilization of entrapped cells, maintaining of specific growth, high cells densities and lack of contamination. Additionally, immobilized cells are less susceptible than free cells to the effect of substrate inhibition and $\mathrm{pH}$ variations, all these help to improve the overall process. Presently, natural and synthetic polymers such as cellulose, alginate, chitosan, agarose polyurethane, and polyacrylate are being used for cell immobilization with calcium alginate beads being widely used in immobilization of bacteria, yeast, fungi and algae for different bioprocesses (Gòdia et al. 1987; Pacheco et al. 2010; Galaction et al. 2012; Duarte et al. 2013). These polymers have potential application in bioethanol production, vinegar production, and wastewater treatment due to its simplicity, cheap, non-toxic to cells and good mechanical properties. However, there are some disadvantages with their use, such as gel degradation, severe mass transfer limitations, low mechanical strength as it can cause the release of cells from the support and large pore size. To overcome this, a combination of chitosan, a polycationic polymer and alginate, a polyanionic polymer is diffused into the alginate beads to provide a strong ionic interaction between chitosan amino groups and carboxyl groups of alginate which forms a polyelectrolyte complex (PEC) that gives more mechanical support to cells (Yu et al. 2007; Galaction et al. 2012; Duarte et al. 2013).
For several decades, traditional setups like membrane, air lift and stirrer tank bioreactors have been used in bioethanol production. However, some drawbacks like, less product yield due to low mass and heat transfer, inefficient conversion of substrate, uneven mixing and shear stress on biocatalysts have been observed. Therefore, there is need in utilizing a reactor that is able to sustain an excellent hydrodynamic regime coupled to reduced overall mass transfer limitations (Saini and Vieth 1975; Pilkington et al. 1998; Karagoz and Ozkan 2014). In this article, we used the packed bed bioreactor (PBR) with one bed containing immobilized beads and a vessel for culture medium, in which the culture medium is circulated from the vessel through the fixed bed and back (Figure 1).

Medium enriched with glucose re-enter the packed bed where it can be re-utilized to convert glucose into ethanol. Toxic metabolites and other by-products are diluted; oxygen and $\mathrm{pH}$ can be adjusted to optimal levels. This reactor has several advantages over other bioreactors like, low manufacturing and operating cost, automation process and facility to operate at low temperatures. The preference for fixed bed bioreactor has increased due to its higher sensitivity/effectiveness of immobilized cells or enzymes (Cascaval et al. 2012).

In this article we focused on the operational performance of the immobilized packed-bed bioreactor in the course of physiological and biochemical studies on the substrate uptake of immobilized yeast cells. The reactor was operated in batch mode fermentation; yeast physiology and mass transfer behavior in packed bed reactor were monitored in close relation to parameters such as glucose concentration, medium flow rate and different support materials like alginate beads with and without chitosan coating.

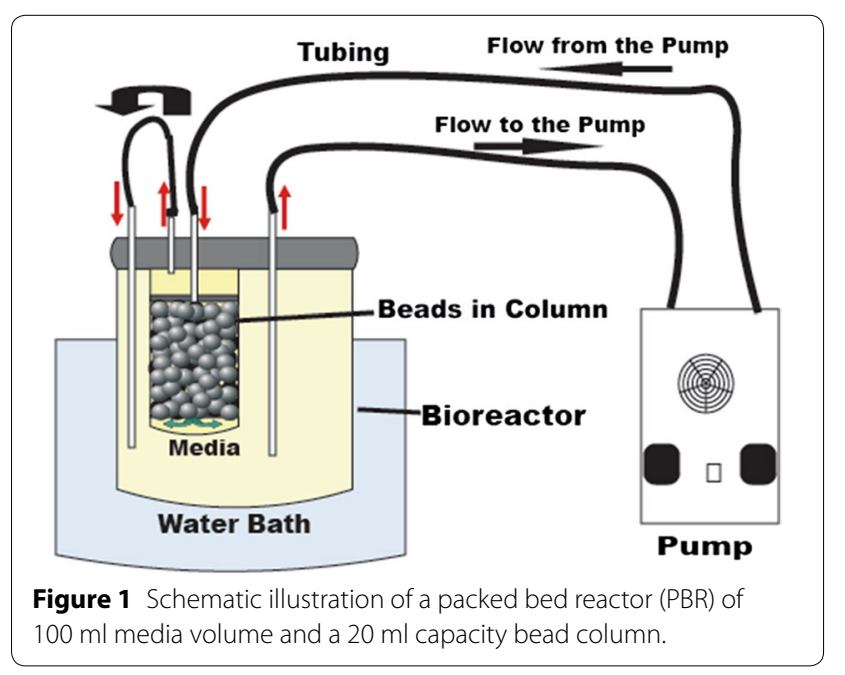




\section{Materials and methods Materials \\ Microorganism}

The yeast $S$. cerevisiae (baker yeast) was obtained from DHW Vital Gold, Nürnberg, Germany, while the S. cerevisiae Ethanol Red 11 strain was purchased from Fermentis Inc, Marcq-en-Baroeul, France and were stored at 4 and $-80^{\circ} \mathrm{C}$, respectively.

\section{Fermentation medium and cultivation}

Minimal media was prepared with $6.7 \mathrm{~g} / \mathrm{l}$ yeast extract nitrogen base without amino acid, $1.7 \mathrm{~g} / \mathrm{l}$ ammonium acetate and glucose $(2,4,10,20$ and $40 \mathrm{~g} / \mathrm{l})$ were prepared separately and mixed after sterilizing $\left(121^{\circ} \mathrm{C}, 20 \mathrm{~min}\right)$. Amino acid mixture $(100 \times)$ was prepared by mixing the following different amino acids; $200 \mathrm{mg}$ L-arginine, 1,000 mg L-aspartic acid, $1,000 \mathrm{mg}$ L-glutamic acid, $300 \mathrm{mg}$ L-lysine, $500 \mathrm{mg}$ L-phenylalanine, 4,000 $\mathrm{mg}$ L-serine, 2,000 $\mathrm{mg}$ L-threonine, $300 \mathrm{mg}$ L-tyrosine, $1,500 \mathrm{mg} \mathrm{L}$-valine, dissolved in water by adjusting pH 10 with $0.1 \mathrm{~N} \mathrm{NaOH}$ and used $0.2 \mu \mathrm{m}$ filter for sterilization. During culturing, $10 \mathrm{ml}$ of amino acids solution was added to a final 11 media.

Ethanol Red 11 strain was refreshed by streaked onto YPD agar plate (1\% yeast extract, $2 \%$ peptone and $2 \%$ glucose, $2 \%$ agar), incubated for 2 days at $35^{\circ} \mathrm{C}$. The resulting single colonies were used to start a fresh culture. Twenty milliliters of YPD media ( $1 \%$ yeast extract, $2 \%$ peptone and $10 \% \mathrm{D}$-glucose) in a $100 \mathrm{ml}$ flask was inoculated with a single colony of Yeast Ethanol Red 11 grown overnight at $35^{\circ} \mathrm{C}$ with vigorous shaking at $250 \mathrm{rpm}$. One percent of the pre-culture was used to inoculate 21 Erlenmeyer baffled flask containing 1,000 ml YPD media final volume. The inoculated flask was incubated on a rotary shaker at $200 \mathrm{rpm}$ and $35^{\circ} \mathrm{C}$ for $24 \mathrm{~h}$. Furthermore, the cells were collected by centrifugation at $4,000 \mathrm{rpm}$ for $15 \mathrm{~min}$, washed twice with sterile distilled water, centrifuged and re-suspended in sterile water to obtain a dense cell suspension.

\section{Calcium alginate beads preparation and yeast immobilization}

A sterile sodium alginate solution $(2.5 \% \mathrm{w} / \mathrm{v}$, autoclaved at $121^{\circ} \mathrm{C}$, for $15 \mathrm{~min}$, was prepared in $50 \mathrm{mM}$ phosphate buffer at $\mathrm{pH} 7$. For yeast immobilization, $3 \%$ final amount of the above obtained cell suspension were mixed with alginate solution. For beads preparation, alginate-yeast solution was drop by drop allowed to dip using $1 \mathrm{ml}$ pipette tip into $200 \mathrm{ml}, 180 \mathrm{mM} \mathrm{CaCl}_{2}$. Beads were let to harden in this solution for $1 \mathrm{~h}$. Beads were further rinsed three times with sterile $2 \% \mathrm{NaCl}$ solution and then with sterile water. The alginate beads with diameters between 3 and $4 \mathrm{~mm}$ were used in experiments. For the preparation of alginate beads with chitosan coating, the above prepared beads were dipped in sterilized chitosan solution (3\% chitosan, $0.1 \mathrm{~N} \mathrm{HCl}, \mathrm{pH} 5$ ) for $10 \mathrm{~min}$ and later washed 3 times with sterile water.

\section{Packed bed reactor and beads packaging}

A packed bed bioreactor $(100 \mathrm{ml})$ was purchase from Medorex GmbH, Noerden-Hardenberg, Germany. The bioreactor column has a $2 \mathrm{~cm}$ diameter glass vessel for beads package, with one end close and other closed by rubber plug (Figure 1). The reactor was $2 / 3$ filled with beads and temperature was kept at $35^{\circ} \mathrm{C}$ using a water bath. The immobilized yeast was grown on minimal media with varying factors: glucose $(2,4,10,20$ and $40 \mathrm{~g} / \mathrm{l})$, flow rate $(1,4,12,30$ and $90 \mathrm{ml} / \mathrm{min}$.) and alginate bead with and without chitosan coating while factors like initial cells amount $(3 \%)$ and temperature $\left(35^{\circ} \mathrm{C}\right)$ were kept constant.

\section{Glucose consumption measurements}

For immobilized yeast glucose consumption measurements, the DNS method was used. For each measurement, $0.5 \mathrm{ml}$ sample and $0.5 \mathrm{ml}$ DNS solution were mixed in a $1.5 \mathrm{ml}$ Eppendorf tube, vortex for $10 \mathrm{~s}$, and incubated for $10 \mathrm{~min}$ at $90^{\circ} \mathrm{C}$. After incubation, $40 \% 0.16 \mathrm{ml}$ potassium sodium tartrate was added, mixed by vortex and placed on ice for $3 \mathrm{~min}$. Two hundred microliter of each sample was measured at $575 \mathrm{~nm}$. The obtained results were compared with calibration curve of different glucose concentration to get actual concentration.

\section{Ethanol production measurements}

For measurement of ethanol concentration produced in fermentation broth as well as calibration curve preparation, the underlined method was used. Six hundred microliter of fermentation broth samples were collected, transferred to an Eppendorf tube and centrifuged at $9,000 \mathrm{rpm}$ for a min to pellet the cells. Later, $500 \mu \mathrm{l}$ of the clear supernatant were transferred into a new tube without disturbing the cell pellet, and $5 \mu \mathrm{l}$ of $1 \% n$-butanol was added as an internal standard. The samples were vortexed for $30 \mathrm{~s}$ and $1 \mathrm{ml}$ of $25 \%$ ethyl acetate was added with a further 5 min vortexing. For phase separation, the samples were centrifuged at 5,000 rpm and the organic phase was used for gas chromatography (GC). For sample measurements, gas chromatograph equipped with flame ionization detector (FID) was used. The columns used were the 30 and $0.25 \mathrm{~mm}$ CP-WAX-57CB (Santa Clara, CA, USA). During liquid analysis, temperature programming was employed and the column temperature was initially maintained at $120^{\circ} \mathrm{C}$ for $2 \mathrm{~min}$ and later the oven temperature was increased at a rate of $10^{\circ} \mathrm{C} / \mathrm{min}$ until it reached $150^{\circ} \mathrm{C}$. The injector and detector temperature were kept at 150 and $200^{\circ} \mathrm{C}$, respectively. The flow rate 
for carrier gas (helium) was set at $30 \mathrm{ml} / \mathrm{min}$. The injection sample volume was $2 \mu \mathrm{l}$. Each set of the experiment and data points were repeated thrice and the reported value was the mean average.

\section{Results}

Effect of chitosan coating on lag phase and glucose consumption

Sequential fermentation experiments with two parameters; flow rate and glucose concentration were varied to understand the effect on lag phase and glucose consumption rate till $\mathrm{C} / \mathrm{C}_{0}$ of 0.1 in both chitosan and non-chitosan coated calcium alginate beads, where $\mathrm{C}_{0}$ represent the initial glucose concentration at time zero, $\mathrm{C}$ is the concentration at a particular time and $0.1(10 \%)$ is the remaining glucose in the media. Figure $2 \mathrm{a}-\mathrm{d}$ shows the flow rates used to determine the effect of chitosan coating on glucose consumption and from the curves we observed two phases: lag and exponential phase. After lag phase, no significant change was observed in both types of beads on glucose consumption with the same flow rate. Additionally, it was also observed that by increasing flow rates; lag phase and glucose consumption time decreased (Figure 2c, d).
Effect of flow rate and glucose concentration on lag phase The results in Figure 3a, b shows two parameters; flow rate and glucose concentration, varied from 1 to $90 \mathrm{ml} /$ min and 2 to $40 \mathrm{~g} / \mathrm{l}$, respectively, having a tremendous effect on lag phase. In the study, it was observed that lag phase of both types of beads decreases by increasing flow rate, moreover longer lag phase was found at higher glucose medium concentration. The maximum time of lag phase was found to be $290 \mathrm{~min}$ at lower flow rate of $1 \mathrm{ml} / \mathrm{min}$ and $190 \mathrm{~min}$ at higher flow rate $90 \mathrm{ml} / \mathrm{min}$ when using $40 \mathrm{~g} / \mathrm{l}$ of glucose. It was also observed that by decreasing glucose concentration from 40 to $10 \mathrm{~g} / \mathrm{l}$, lag phase decreased too. Furthermore, no lag phase was found at glucose concentration of 4 and $2 \mathrm{~g} / \mathrm{l}$ (Figures 2, 3). As shown in Figure 3, non-chitosan coated beads have shorter lag phase as compared to coated beads, indicating an improved mass transfer effect observed at higher flow rate and less inhibition of glucose transfer. While higher flow rate was shown to have a major effect in reducing time on lag phases in both types of beads (Figures 2, 3). To support the above data, fermentation results of the Ethanol Red 11 yeast strain was compared with Baker's yeast using flow rates of 4 and $90 \mathrm{ml} / \mathrm{min}$ and glucose concentration of 4 and $10 \mathrm{~g} / \mathrm{l}$. The results show that there
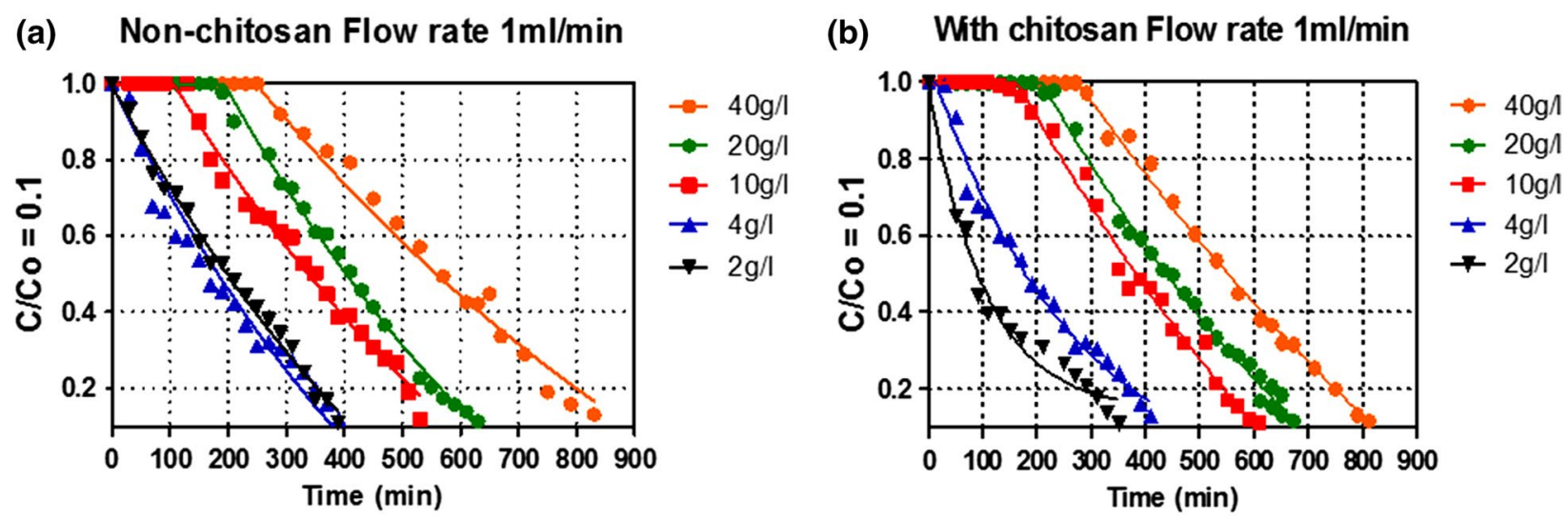

(c) Non-chitosan, flow rate $90 \mathrm{ml} / \mathrm{min}$
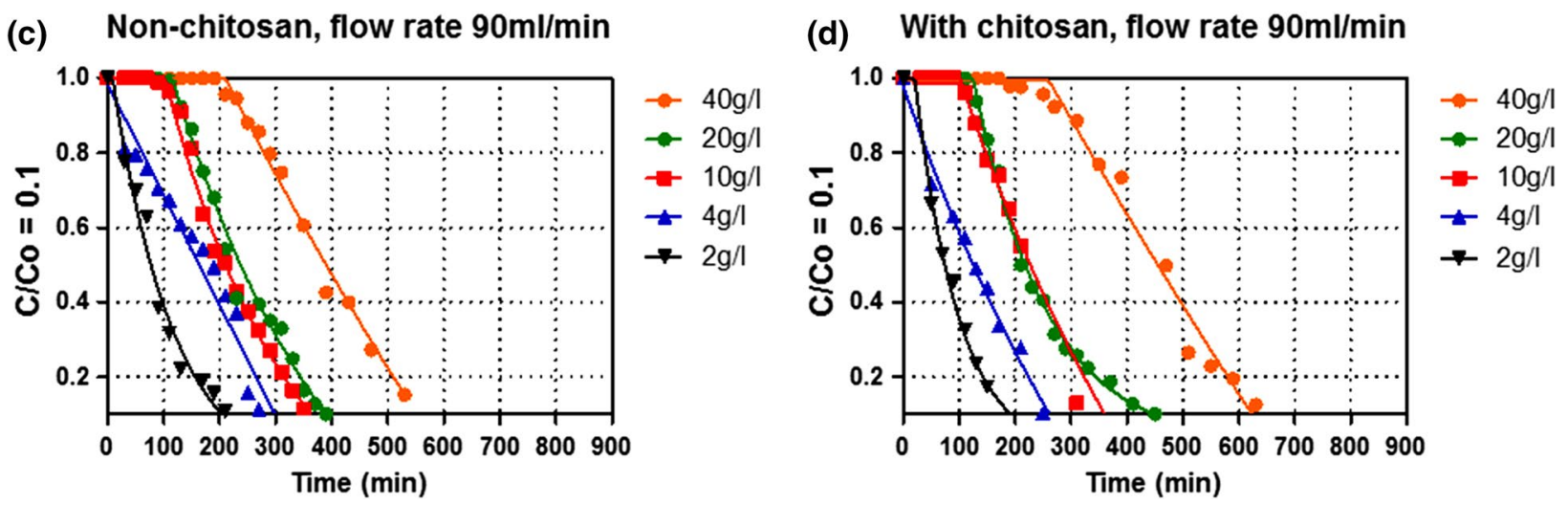

Figure 2 Fermentation profile of immobilized Saccharomyces cerevisiae cells in PBR. Effect of flow rate on beads with (a, $\mathbf{c})$ and non-chitosan (b, $\mathbf{d})$. 


\section{(a) Effect of flow rate (Non-chitosan)}

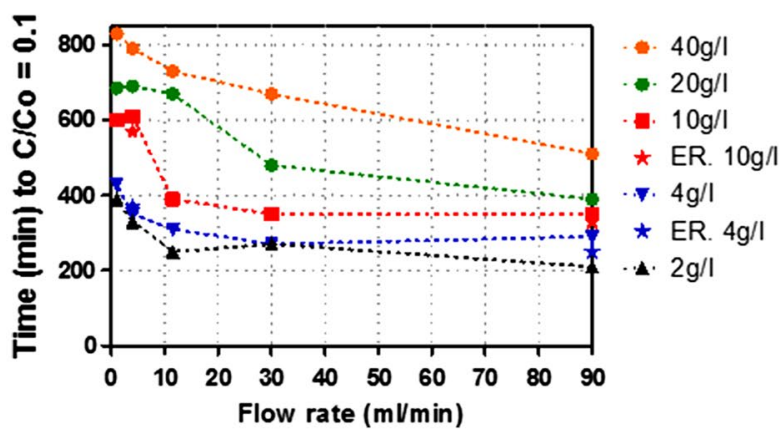

(b) Effect of flow rate (Chitosan coated)

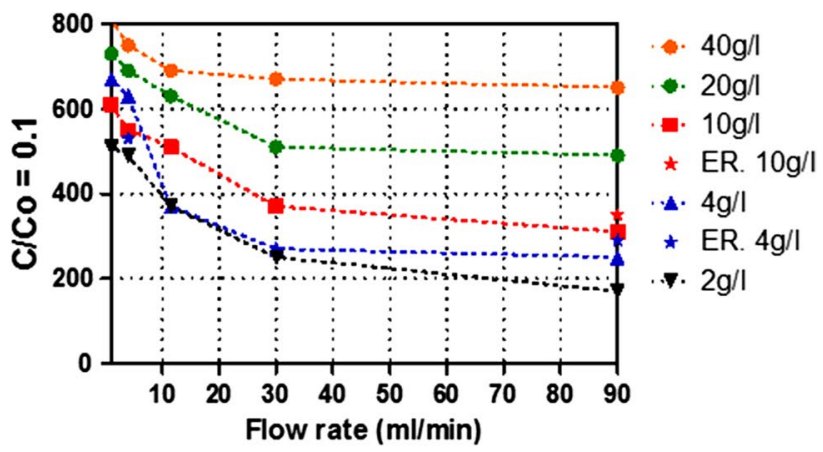

Figure 3 Fermentation profile of immobilized Saccharomyces cerevisiae cells in PBR. Effect of flow rate on lag phase using beads with (a) and without chitosan $(\mathbf{b})$

is no significant difference in lag phase of two types of yeast.

\section{Effect of flow rate and glucose concentration on glucose consumption}

In this study, glucose consumption of up to the level of $\mathrm{C} / \mathrm{C}_{0}=0.1$ was measured so as to understand the performance of the bioreactor and mass transfer properties regarding chitosan and non-chitosan coated beads. Figure 4 shows that by varying the flow rate from 1 to $90 \mathrm{ml} / \mathrm{min}$, time for glucose consumption decreased. The major difference in glucose consumption behavior was observed when using both types of beads at higher flow rate like $90 \mathrm{ml} / \mathrm{min}$. Time for glucose consumption by chitosan coated beads, at 30 and $90 \mathrm{ml} / \mathrm{min}$ is rather equal when using higher glucose concentration i.e. 40 and $20 \mathrm{~g} / \mathrm{l}$ as compared to lower glucose concentration 10, 4 and $2 \mathrm{~g} / \mathrm{l}$. Moreover, beads' having no layer of chitosan, glucose consumption time tends to decrease by increasing flow rate. Further experiments have been performed to compare the S. cerevisiae Ethanol Red strain and wild type Baker's yeast using parameter glucose consumption time. Both strains performance were observed to be relatively equal at 4 and $10 \mathrm{~g} / \mathrm{l}$ glucose.

\section{Effect of flow rate and glucose concentration on ethanol productivity and yield}

The minimal medium was used in all experiments so that yeast growth rate was at its minimal and cells inside the beads were assumed to be uniform. Experiments were conducted using the above mentioned yeast strains having initial glucose concentrations 4 and $10 \mathrm{~g} / \mathrm{l}$ and flow rate 4 and $90 \mathrm{ml} / \mathrm{min}$ with dilution rate of 0.2 and $4.5 \mathrm{~h}^{-1}$, respectively. The effect of flow rate and dilution rate at different glucose concentration on ethanol productivity as well as on ethanol yield is presented in Table 1. It can be observed that when the initial glucose concentration was 4 and $10 \mathrm{~g} / \mathrm{l}$, the ethanol productivity increase linearly with the dilution rate from 0.2 to $4.5 \mathrm{~h}^{-1}$. An optimal ethanol productivity of $21.9 \mathrm{~g} /(\mathrm{g} \mathrm{h})$ was obtained when using Ethanol Red strain at D of $4.5 \mathrm{~h}^{-1}$ with glucose concentration of $10 \mathrm{~g} / \mathrm{l}$. It was also observed that there was
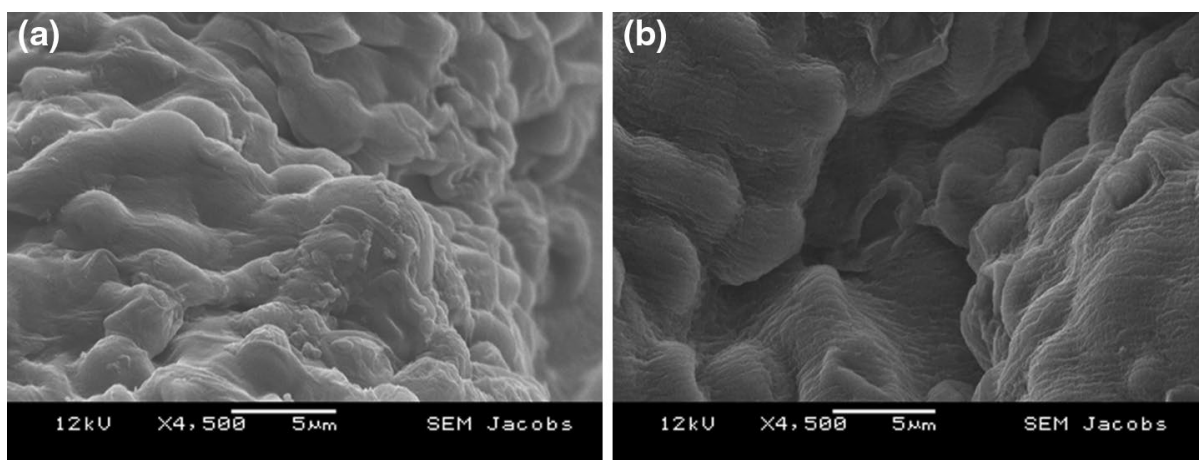

Figure 4 Fermentation profile of immobilized Saccharomyces cerevisiae cells in PBR. Effect of flow rate on glucose consumption on beads (a) with and, (b) without chitosan. 
Table 1 Ethanol productivity and yield by yeast strains

\begin{tabular}{|c|c|c|c|c|c|c|}
\hline \multirow[t]{3}{*}{ Flow rate $(\mathrm{ml} / \mathrm{min})$} & \multirow{3}{*}{$\begin{array}{l}\text { Dilution rate }=\text { flow } \\
\text { rate/bed volume }\end{array}$} & \multirow[t]{3}{*}{ Glucose conc. (g/l) } & \multirow{2}{*}{\multicolumn{2}{|c|}{$\begin{array}{l}\text { Ethanol productivity } \\
D \times P=(g / g \text { yeast } h) \text { at: } \\
300 \text { min }\end{array}$}} & \multirow{2}{*}{\multicolumn{2}{|c|}{$\begin{array}{l}\text { Ethanol yield } \\
\mathrm{Y}(\mathrm{p} / \mathrm{s})=\mathrm{PI}-\mathrm{Po} / \mathrm{So}-\mathrm{SI} \\
\text { at: } 300 \mathrm{~min}\end{array}$}} \\
\hline & & & & & & \\
\hline & & & B.Yeast & ER.Yeast & B.Yeast & ER.Yeast \\
\hline 4 & 0.2 & 4 & 0.38 & 0.4 & 1.11 & 1.2 \\
\hline 4 & 0.2 & 10 & 0.56 & 0.64 & 1.0 & 1.2 \\
\hline 90 & 4.5 & 4 & 10.8 & 12.6 & 0.63 & 0.73 \\
\hline 90 & 4.5 & 10 & 17.1 & 19.8 & 0.48 & 0.55 \\
\hline
\end{tabular}

$D$ dilution rate, $P$ product concentration.

no significant difference in ethanol productivity for both S. cerevisiae strains at lower flow rate i.e. $4 \mathrm{ml} / \mathrm{min}$, while higher productivity was obtained at higher flow rate (90 $\mathrm{ml} / \mathrm{min})$.

\section{Discussion}

In recyclable biocatalyst, the mechanical strength of calcium alginate beads had not fully been found to effectively support entrapped cells. To solve this problem, we focused on using Baker's yeast immobilized in chitosan coated alginate beads of $4 \mathrm{~mm}$ in diameter to facilitate the needed mechanical support. However, the chitosan coating may cause resistance in external mass transfer. The results in Figure 2 indicates that coating has a significant effect on lag phase duration, as it was observed with chitosan coated beads being 30-40 min higher than non-coated beads. The reason is due to the reduction of external mass transfer as a result of increase in flow rate as glucose is easily transported to and from the beads surface by diffusion (Willaert and Flickinger 2009; Galaction et al. 2012; Karagoz and Ozkan 2014).

Our results show an improvement over some literature data, were it was observed that chitosan-covered alginate beads have longer glucose conversion time when compared to alginate beads (Duarte et al. 2013). From the results it can be observed that chitosan acts as barrier for transfer of substrate and products, in and out of beads, at initial time of fermentation as it shows longer lag phase for chitosan coated beads than non-coated. This study gives the significant understanding of both alginate beads with and without chitosan coating as indicated in the differences in lag phases. A number of researchers have been using chitosan coating on alginate beads in order to reduce cell and enzyme release but it has disadvantage on mass transfer and may have an impact on the metabolic activity of cells in beads due to limited substrate supply that ultimately may have an effect on product formation.

Lag phase is considered as the adaptation time of yeast within new environment before the start of fermentation process. The similar effect in Figure 3 was also observed by Irfan et al. (2014) indicating that sugar concentration is critical in fermentation process as it has influence on yeast physiological, growth, rate of production and yield.

The dependence of lag phase on glucose concentration (Figures 2,3) might be as a result of substrate diffusion and increase in concentration gradient between surface and inner regions of beads (Galaction et al. 2012). The observed prolonged lag phase might be due to higher accumulation of cAMP level stimulated by the effect of glucose on cAMP synthesis as the level of cAMP is higher during initial fermentation time (Ma et al. 1997) i.e. lag phase time and decreased on initiation of exponential growth in yeast cells (Duarte et al. 2013; Djordjevic et al. 2014; Mukherjee et al. 2014).

This summarizes the fact that inter-particle diffusional resistance reduces by increasing velocity around beads (Saini and Vieth 1975; Zhao and Delancey 2000; Galaction et al. 2012). Consequently, chitosan coated beds have more inter-particle diffusional resistance i.e. longer lag phase at early times of fermentation as compare to non-coated at lower flow rate. At this point it can be concluded that lag phase is not due to the physiology of yeast, but it may be due to the resistance in internal diffusion of glucose. This could be due to the fact that lag phase is directly depending on the glucose concentration as well as on flow rate.

Glucose is the most fundamental carbon source playing a central role in metabolic pathways providing energy to living organisms, and for product synthesis. Yeast metabolize glucose via the Embden-Mereyhof Parnas metabolic pathway (Galaction et al. 2012) there-by producing energy necessary for it survival. Furthermore, the efficiency of ethanol production can be affected by glucose concentration and flow rate. From the ethanol production experiments, it was observed that the time for glucose consumption by chitosan coated beads, at 30 and $90 \mathrm{ml} / \mathrm{min}$ was rather equal when using higher glucose concentration i.e. 40 and $20 \mathrm{~g} / \mathrm{l}$ as compared to lower glucose concentration 10, 4 and $2 \mathrm{~g} / \mathrm{l}$. This might be due to glucose diffusion resistance that did not reduce 
even when using higher flow rate. However, this result indicates that chitosan coating characteristics influences glucose internal diffusion at higher glucose concentration. In literature, it was also observed that magnitude of glucose diffusion resistance is directly related to glucose concentration gradient created in and outside of beads (Galaction et al. 2011), indicating substrate inhibition phenomenon, affecting the fermentation performance. In non-chitosan coated beads' when compared with coated beads, glucose consumption time tends to decrease by increasing flow rate. The reason might be due to the fact that these types of beads did not pose any significant barrier (Figure 5) for glucose diffusion to metabolically active cells. This result was supported by Chen et al. (2012) observation that under scanning electron microscopy (SEM), surface of chitosan-coated beads was rough and compact compared to the non-coated alginate beads, due to strong electrostatic interaction between chitosan and alginate. The interpretation of these results indicates that glucose consumption behavior was not due to the yeast strain, but to mass transfer barrier that might have occurred by layer of chitosan coating on alginate beads and glucose concentration inhibition phenomenon.

As indicated in Table 1, higher ethanol productivity was observed on increasing flow rate and glucose concentration. A higher productivity can be attributed to the improved mass transfer properties when using higher flow rate that might be due to reduced substrate diffusional resistance (Anselme and Tedder 1987; Yu et al. 2007; Matsushika et al. 2009; Pacheco et al. 2010; Bangrak et al. 2011; Mathew et al. 2014). Although higher glucose concentration can give higher productivity, it can also facilitate increase in inter-particle diffusional resistance that enhances the lag phase as shown in Figures 2 and 3. It was also found the enhancement of ethanol production on increasing liquid velocity decrease mass transfer resistance and substrate inhibitory effect (Bangrak et al. 2011).

Duarte et al. (2013) found that the maximum ethanol production during fermentation was after $4 \mathrm{~h}$ for nonchitosan coated alginate beads while for coated ones was after $6 \mathrm{~h}$. While it was also reported that hydrodynamics of medium exhibits an important influence on glucose conversion and transfer processes (Cascaval et al. 2012; Galaction et al. 2012; Mathew et al. 2014).

Furthermore, in the case of ethanol yield, the industrial strain Ethanol Red 11 strain has higher yield than Baker's yeast at all flow rate and glucose concentration. On the other hand at $4 \mathrm{ml} / \mathrm{min}$ flow rate and $10 \mathrm{~g} / \mathrm{l}$ glucose, ethanol yield of both yeast strains was observed to be high as compare to flow rate of $90 \mathrm{ml} / \mathrm{min}$ with same glucose. This result is due to higher residence time up to which yield is high (Singh et al. 2009).

Ethanol yield for both strains has been observed to decrease on addition of glucose that might be due to increased substrate diffusional resistance. The magnitude of resistance is directly related to the glucose concentration gradient between the inner and outer regions of beads, consequently concentration gradient can induce substrate inhibition and it was found that there was significant decrease in ethanol yield on addition of sugar concentration in fermentation medium. (Bangrak et al. 2011; Galaction et al. 2011, 2012 Rotaru et al. 2011; Cascaval et al. 2012).

It was also reported that in batch fermentation of $S$. cerevisiae, the ethanol yield was significantly depended on initial glucose concentration and substrate inhibition was notices at high initial glucose concentration (Wendhausen et al. 2001).

Sequential experiments on varying flow rates and glucose in a packed bed bioreactor with immobilized S. cerevisiae cells shades significant understanding on mass

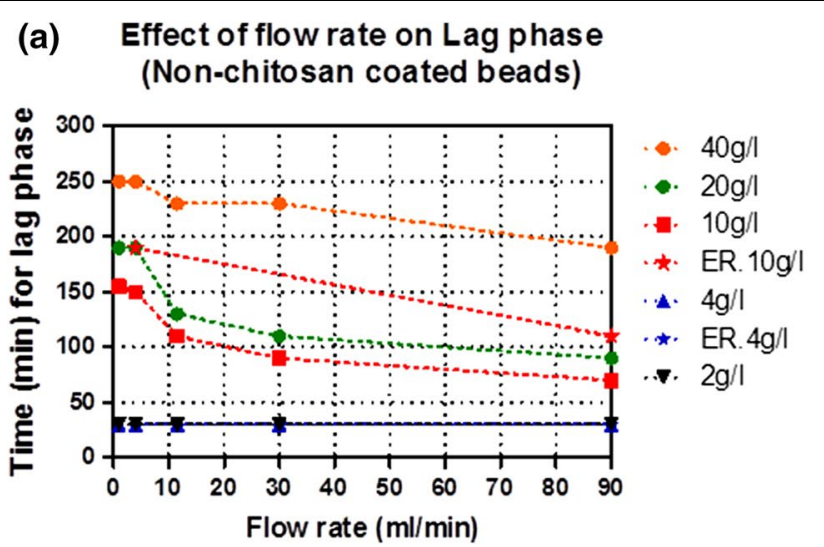

(b) Effect of flow rate on Lag phase (Chitosan coated beads)

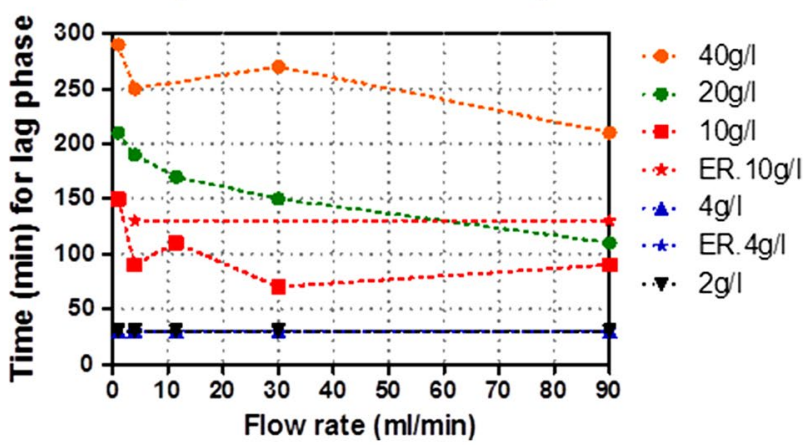

Figure 5 Scanning electron microscopic (SEM) photographs of non-coated alginate beads (a), chitosan coated beads (b). 
transfer. Moreover, glucose consumption at low flow rate was lower when compared to when higher flow rates were used. By means of the analysis of the influence of different concentration of glucose and varying flow rate, the optimum combination was found to be that consisting of higher flow rates and between 10 and $20 \mathrm{~g} / \mathrm{l}$ of glucose. This combination leads to the optimum glucose consumption rate and maximum product formation. The selected system for mixing as well as glucose concentration will be used in the further experiments for internal mass transfer or active pharmaceutical ingredient production in this basket bioreactor.

\section{Authors' contributions}

$A H, M K$ and MFL have designed the work. AH, AG carried out the experiment. $A H, A G, M K$ and MFL analyzed the data and contributed for the statistical analysis. AH, MK and MFL wrote the manuscript and reviewed the manuscript critically. All the authors have read the article and approved the final manuscript.

\section{Author details}

${ }^{1}$ Downstream Bioprocessing Laboratory, School of Engineering and Science, Jacobs University, Campus Ring 1, 28759 Bremen, Germany. ${ }^{2}$ Department of Biotechnology, Faculty of Agriculture, Al-Azhar University, Naser City, Cairo 11884, Egypt.

\section{Acknowledgements}

Partial support for this study was provided from Project PGSYS-EXCHANGE EU-PIRSES\#269211, ERA Net Euro TransBio-3, PGYSYS and Jacobs University Bremen.

\section{Compliance with ethical guidelines}

\section{Competing interests}

The authors declare that they have no competing interests.

Received: 1 December 2014 Accepted: 26 February 2015

Published online: 01 May 2015

\section{References}

Anselme MJ, Tedder DW (1987) Characteristics of immobilized yeast reactors producing ethanol from glucose. Biotechnol Bioeng 30(6):736-745

Bangrak P, Limtong S, Phisalaphong M (2011) Continuous ethanol production using immobilized yeast cells entrapped in loofa-reinforced alginate carriers. Braz J Microbiol 42(2):676-684

Borovikova D, Scherbaka R, Patmalnieks A, Rapoport A (2014) Effects of yeast immobilization on bioethanol production. Biotechnol Appl Biochem 61(1):33-39

Cascaval D, Galaction Al, Turnea M (2012) Influences of internal diffusion on the lipids bio-degradation with immobilized Bacillus sp. cells in fixed bed of basket type. Rev Med Chir Soc Med Nat lasi 116(1):228-232

Cha HG, Kim YO, Lee HY, Choi WY, Kang DH, Jung KH (2014) Ethanol production from glycerol by the yeast Pachysolen tannophilus immobilized on celite during repeated-batch flask culture. Mycobiology 42(3):305-309

Chen XH, Wang XT, Lou WY, Li Y, Wu H, Zong MH, Chen XD (2012) Immobilization of Acetobacter sp. CCTCC M209061 for efficient asymmetric reduction of ketones and biocatalyst recycling. Microb Cell Fact 11:119

Converti A, Perego P, Lodi A, Parisi F, del Borghi M (1985) A kinetic study of Saccharomyces strains: performance at high sugar concentrations. Biotechnol Bioeng 27(8):1108-1114

Crespo CF, Badshah M, Alvarez MT, Mattiasson B (2012) Ethanol production by continuous fermentation of $\mathrm{D}-(+)$-cellobiose, $\mathrm{D}-(+)$-xylose and sugarcane bagasse hydrolysate using the thermoanaerobe Caloramator boliviensis. Bioresour Technol 103(1):186-191

De Bari I, De Canio P, Cuna D, Liuzzi F, Capece A, Romano P (2013) Bioethanol production from mixed sugars by Scheffersomyces stipitis free and immobilized cells, and co-cultures with Saccharomyces cerevisiae. N Biotechnol 30(6):591-597

de Jong B, Siewers V, Nielsen J (2012) Systems biology of yeast: enabling technology for development of cell factories for production of advanced biofuels. Curr Opin Biotechnol 23(4):624-630

Djordjevic R, Gibson B, Sandell M, De Billerbeck GM, Bugarski B, LeskosekCukalovic l et al (2014) Raspberry wine fermentation with suspended and immobilized yeast cells of two strains of Saccharomyces cerevisiae. Yeast 32(1):271-279

Duarte JC, Rodrigues JA, Moran PJ, Valenca GP, Nunhez JR (2013) Effect of immobilized cells in calcium alginate beads in alcoholic fermentation. AMB Express 3(1):31

Galaction Al, Rotaru R, Kloetzer L, Vlysidis A, Webb C, Turnea M et al (2011) External and internal glucose mass transfers in succinic acid fermentation with stirred bed of immobilized Actinobacillus succinogenes under substrate and product inhibitions. J Microbiol Biotechnol 21(12):1257-1263

Galaction Al, Kloetzer L, Turnea M, Webb C, Vlysidis A, Cascaval D (2012) Succinic acid fermentation in a stationary-basket bioreactor with a packed bed of immobilized Actinobacillus succinogenes: 1. Influence of internal diffusion on substrate mass transfer and consumption rate. J Ind Microbiol Biotechnol 39(6):877-888

Gòdia F, Casas C, Castellano B, Solà C (1987) Immobilized cells: behaviour of carrageenan entrapped yeast during continuous ethanol fermentation. Appl Microbiol Biotechnol 26(4):342-346

Hasunuma T, Kondo A (2012) Development of yeast cell factories for consolidated bioprocessing of lignocellulose to bioethanol through cell surface engineering. Biotechnol Adv 30(6):1207-1218

Irfan M, Nadeem M, Syed Q (2014) Ethanol production from agricultural wastes using Sacchromyces cervisae. Braz J Microbiol 45(2):457-465

Karagoz P, Ozkan M (2014) Ethanol production from wheat straw by Saccharomyces cerevisiae and Scheffersomyces stipitis co-culture in batch and continuous system. Bioresour Technol 158:286-293

Lee SE, Lee CG, Kangdo H, Lee HY, Jung KH (2012) Preparation of corncob grits as a carrier for immobilizing yeast cells for ethanol production. J Microbiol Biotechnol 22(12):1673-1680

Ma P, Goncalves T, Maretzek A, Dias MC, Thevelein JM (1997) The lag phase rather than the exponential-growth phase on glucose is associated with a higher CAMP level in wild-type and CAPK-attenuated strains of the yeast Saccharomyces cerevisiae. Microbiology 143(Pt 11):3451-3459

Mathew AK, Crook M, Chaney K, Humphries AC (2014) Continuous bioethanol production from oilseed rape straw hydrosylate using immobilised Saccharomyces cerevisiae cells. Bioresour Technol 154:248-253

Matsushika A, Inoue H, Kodaki T, Sawayama S (2009) Ethanol production from xylose in engineered Saccharomyces cerevisiae strains: current state and perspectives. Appl Microbiol Biotechnol 84(1):37-53

Mukherjee V, Steensels J, Lievens B, Van de Voorde I, Verplaetse A, Aerts G et al (2014) Phenotypic evaluation of natural and industrial Saccharomyces yeasts for different traits desirable in industrial bioethanol production. Appl Microbiol Biotechnol 98(22):9483-9498

Pacheco AM, Gondim DR, Goncalves LR (2010) Ethanol production by fermentation using immobilized cells of Saccharomyces cerevisiae in cashew apple bagasse. Appl Biochem Biotechnol 161(1-8):209-217

Pilkington PH, Margaritis A, Mensour NA, Russell I (1998) Fundamentals of immobilised yeast cells for continuous beer fermentation: a review. J Inst Brew 104(1):19-31

Pscheidt B, Glieder A (2008) Yeast cell factories for fine chemical and API production. Microb Cell Fact 7:25

Rotaru R, Kloetzer L, Galaction Al, Cascaval D (2011) Succinic acid production using mobile bed of immobilized Actinobacillus succinogenes in alginate. Rev Med Chir Soc Med Nat lasi 115(1):264-268

Saini R, Vieth WR (1975) Reaction kinetics and mass transfer in glucose isomerisation with collagen-immobilised whole microbial cells. J Appl Chem Biotech 25(2):115-141

Shafiee S, Topal E (2008) An econometrics view of worldwide fossil fuel consumption and the role of US. Energy Policy 36(2):775-786

Singh NL, Srivastava P, Mishra PK (2009) Studies on ethanol production using immobilized cells of Kluyveromyces thermotolerans in a packed bed reactor. J Sci Ind Res 68:617-623

Terada A, Yuasa A, Kushimoto T, Tsuneda S, Katakai A, Tamada M (2006) Bacterial adhesion to and viability on positively charged polymer surfaces. Microbiology 152(Pt 12):3575-3583 
Wendhausen R, Fregonesi A, Moran PJ, Joekes I, Rodrigues JA, Tonella E et al (2001) Continuous fermentation of sugar cane syrup using immobilized yeast cells. J Biosci Bioeng 91(1):48-52

Willaert R, Flickinger MC (2009) Cell immobilization: engineering aspects encyclopedia of industrial biotechnology. Wiley, New York
Yu J, Zhang X, Tan T (2007) An novel immobilization method of Saccharomyces cerevisiae to sorghum bagasse for ethanol production. J Biotechnol $129(3): 415-420$

Zhao Y, Delancey GB (2000) A diffusion model and optimal cell loading for immobilized cell biocatalysts. Biotechnol Bioeng 69(6):639-647

\section{Submit your manuscript to a SpringerOpen ${ }^{\circ}$} journal and benefit from:

- Convenient online submission

- Rigorous peer review

- Immediate publication on acceptance

- Open access: articles freely available online

- High visibility within the field

- Retaining the copyright to your article

Submit your next manuscript at $>$ springeropen.com 